\title{
Determination of Small Amounts of Oxygen in Organic Compounds
}

\author{
By William W. Walton, Francis W. McCulloch, and W. Harold Smith
}

\begin{abstract}
A method based on the Unterzaucher procedure has been developed for the determination of small amounts of oxygen in organic compounds. The method involves the pyrolysis of the sample in an atmosphere of helium, conversion of the oxygen compounds that are formed to carbon monoxide by passage of the products over pellets of carbon at a temperature of $1,120^{\circ} \mathrm{C}$, and collection of the carbon monoxide in a flask of known volume. Interfering substances are removed by passage of the gas through a liquid-air or potassium-hydroxide trap before collection of the gas. The percentage of carbon monoxide in the collected gas is determined through use of the NBS colorimetric indicating gel. As little as 0.01 percent of oxygen can be determined readily.
\end{abstract}

\section{Introduction}

In investigations of natural [1] ${ }^{1}$ and synthetic rubbers, of plastics, of petroleum products, and other organic materials, a direct method for the accurate determination of small amounts of oxygen was needed. Such a method has many applications, for example, the determination of traces of oxygen-containing compounds (water, etc.) in purified substances, or in studies of rate of oxidation.

Elving and Ligett [2] critically reviewed methods that have been proposed to determine oxygen in organic compounds and favor a procedure proposed by Schütze [3, 4, 5], which was later modified by Unterzaucher [6]. The essentials of the method are the thermal decomposition of the sample in an atmosphere of oxygen-free nitrogen, passage of the resulting products over carbon heated to $1,120^{\circ} \mathrm{C}$ to convert to carbon monoxide the compounds of oxygen that have been formed, absorption of interfering gases by solid potassium hydroxide, and oxidation of the carbon monoxide to carbon dioxide by iodine pentoxide at a temperature of $118^{\circ}$ C. An important feature of Unterzaucher's apparatus is an arrangement whereby the nitrogen can be passed through the

\footnotetext{
${ }^{1}$ Figures in brackets indicate the literature references at the end of this paper.
}

furnace in reverse to flush out any air that is introduced with the sample.

The accuracy claimed by Unterzaucher for his method has not been obtained by other workers. After a critical investigation of this method, Aluise, Hall, Staats, and Becker [7] recommend the procedure as a satisfactory method for the determination of oxygen in organic compounds, but they state that the results obtained in their laboratory show over-all precision and accuracy somewhat less than those now obtained in carbon and hydrogen analyses. Unpublished work by members of the staff of the National Bureau of Standards has disclosed a number of disadvantages in the use of iodine pentoxide in the determination of small amounts of carbon monoxide - it is difficult to obtain samples of iodine pentoxide that yield low blanks, and frequently samples of iodine pentoxide that are satisfactory will suddenly develop large blanks during use. For the accurate determination of small amounts of oxygen such variability cannot be tolerated.

Recently the Gas Chemistry Section of the National Bureau of Standards developed a colorimetric indicating gel for the detection and estimation of small amounts of carbon monoxide [8]. It is possible by this method to detect and estimate less than 1 part of carbon monoxide in 1,000,000 parts of air. This sensitivity is far greater than 
needed for estimating the carbon monoxide formed in the Unterzaucher procedure even with very small amounts of oxygen-20 milligrams of a sample containing 0.01 percent of oxygen would yield a concentration of carbon monoxide equal to about 1 part in 300,000 if collected in a 1-liter flask.

A procedure was developed for the determination of oxygen based on the Unterzaucher method for converting the oxygen to carbon monoxide and determination of the amount of carbon monoxide with NBS colorimetric indicating gel.

\section{Description of the Apparatus and Method}

A general view of the apparatus is given in figure 1 , and the details are shown in a schematic drawing, figure 2 . remove any oxygen that may be in the helium. Any oxide formed on the copper spirals is reduced when necessary by passing a stream of hydrogen through the heated tube and out to the atmosphere through the two-way stopcock ( 8 , in fig. 2$)$.

The U-tube (10, in fig. 2) has an outside diameter of $25 \mathrm{~mm}$ and a height of $30 \mathrm{~cm}$. The arm of the $U$-tube, connected to stopcock 8 , is packed with ascarite, and the arm connected to stopcock 12 is packed with anhydrous magnesium perchlorate.

Furnace (17, in fig. 2) consists of a cast-iron pipe, with a diameter of $20 \mathrm{~cm}$ and a length of 25 $\mathrm{cm}$, and is closed at both ends with transite board. The transite boards are $20 \mathrm{~mm}$ thick and are drilled to hold the quartz tube and a central core. This central core is an Alundum tube, 1 in. in diameter with grooves of $1 / 12$-in. pitch. It is wound with about 30 feet of 90 -percent platinum-

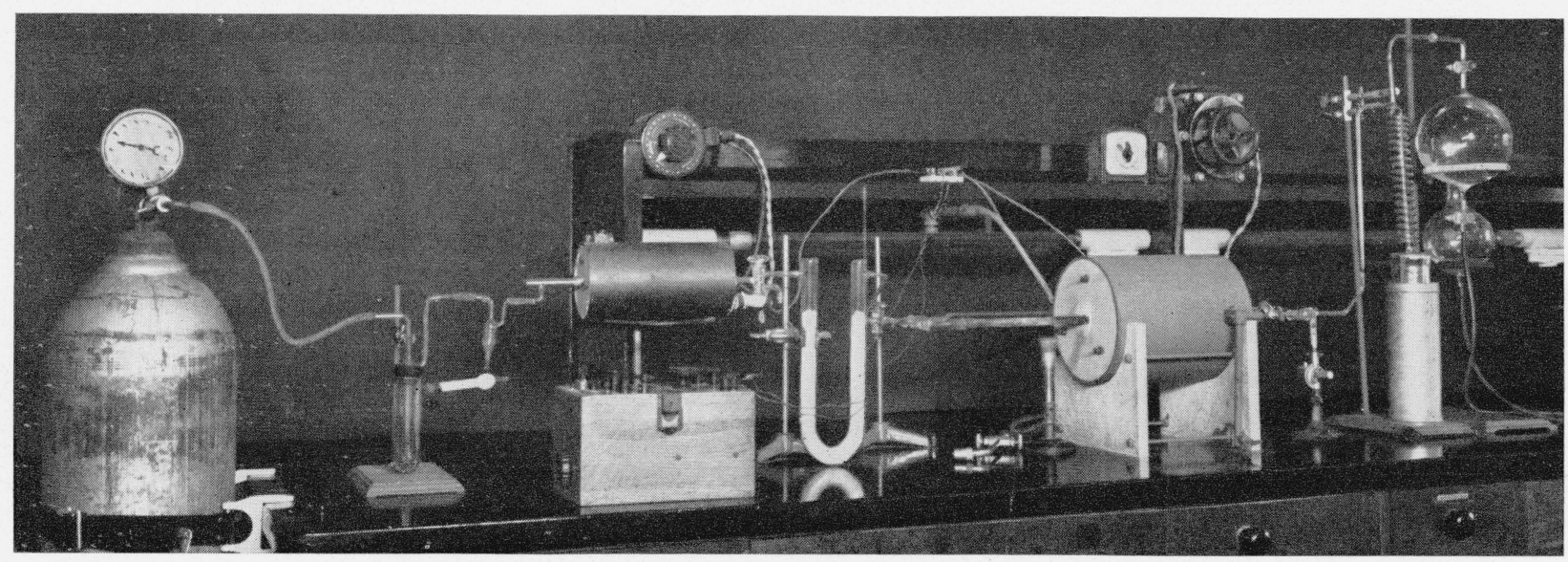

FIGURE 1. Apparatus for the determination of small amounts of oxygen in organic compounds.

The rubber connections used by Unterzaucher were avoided, because water and oxygen diffuse through rubber. Helium was substituted for nitrogen because of its inertness, its greater freedom from oxygen, and the possibility that it would be more efficient in the removal of adsorbed oxygen.

Furnace (5, in fig. 2) is a Nichrome-wire-wound type, $22 \mathrm{~cm}$ in length, and is operated at a temperature of $400^{\circ} \mathrm{C}$. The tube in this furnace is made of 10-mm Pyrex glass tubing and is about $32 \mathrm{~cm}$ long. It is sealed to the $\mathrm{U}$-tube through a two-way stopcock that allows the gases to be passed either through the $U$-tube or to the atmosphere, and it is filled with small copper spirals to

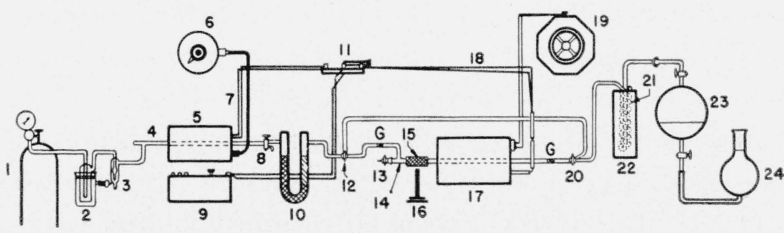

FIGURE 2. Schematic drawing of apparatus for the determination of small amounts of oxygen in organic compounds.

(1) Helium tank; (2) pressure regulator; (3) bubble counter; (4) tube packed with copper spirals; (5) furnace heated to $400^{\circ} \mathrm{C}$; (6) variable transformer for furnace (5); (7) thermocouple for furnace (5); (8) two-way stopcock; (9) potentiometer for measuring the temperatures of furnaces (5) and (17); (10) U-tube filled with ascarite and anhydrous magnesium perchlorate; (11) two-way thermocouple switch; (12) three-way stopcock; (13) stopcock; (14) quartz tube packed with gas-black pellets; (15) wire gauze mantle; (16) burner; (17) furnace heated to $1,120^{\circ} \mathrm{C}$; (18) thermocouple for furnace (17); (19) variable transformer for furnace (17); (20) three-way stopcock; (21) liquid air trap; (22) Dewar flask; (23) collecting flask; (24) water container; $(\mathrm{G})$ graded quartz to pyrex seal. 
10-percent rhodium wire, $0.8 \mathrm{~mm}$ in diameter. The windings should be closer at the ends of the tube than they are at the center. The furnace is insulated with a packing of Santocel and is operated at a temperature of $1,120^{\circ}$ C. Equilibrium, if reached, would leave only a negligible fraction of the oxygen in compounds other than carbon monoxide at any temperature above about $1,000^{\circ} \mathrm{C}$. To be sure of approaching equilibrium during the time that the gases are in the heated zone, a higher temperature is needed. Too high a temperature increases the difficulties with the apparatus. The temperature selected by Unterzaucher was found to be satisfactory.

The liquid-air trap (21, in fig. 2) is a spiral formed from 5 -mm glass tubing and has a diameter of $4 \mathrm{~cm}$. and a length of $25 \mathrm{~cm}$.

The collecting flask is a round flask fitted at both ends with capillary stopcocks. The upper stopcock is sealed to a standard spherical ground-glass joint. Both 1-liter and 2-liter flasks have been used. They are calibrated by filling them with water, draining to a mark on the lower capillary, and weighing the water.

The quartz tube is shown in detail in figure 3 . It is $66.5 \mathrm{~cm}$ long, with an outside diameter of $13 \mathrm{~mm}$ and a wall thickness of $2 \mathrm{~mm}$. Quartz to Pyrex graded seals are used at points 3 and 7 shown in the drawing. The end of the quartz tube through which the sample is introduced is ground to receive a ground-glass joint (2, in fig. 3$)$, which is fitted with a capillary stopcock (1, in fig. 3). The quartz tube is packed with carbon pellets (5, in fig. 3) for a length of $10 \mathrm{~cm}$, starting at a point $31 \mathrm{~cm}$ from the capillary sidearm. The packing is held in place with rolls of platinum gauze ( 4 and 6 , in fig. 3 ) or quartz wool. Carbon from the products of pyrolysis slowly deposits on the platinum gauze (4, in fig. 3) and interferes with the free passage of helium. This deposit is readily removed by withdrawing the platinum gauze and igniting it over a burner.

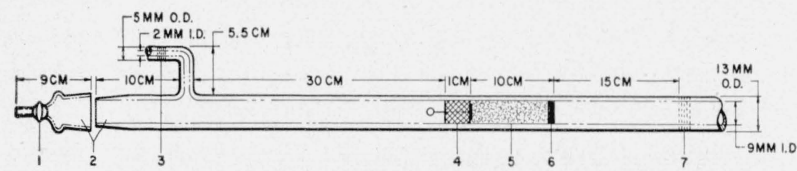

Figure 3. Quartz tube used in the apparatus for the determination of oxygen.

(1) Micro stopeock; (2) ground-glass joint; (3) quartz to Pyrex graded seal; (4) platinum gauze or quartz wool; (5) carbon pellets; (6) platinum gauze or quartz wool; (7) quartz to Pyrex graded seal.
Detailed directions for the use of the indicating gel tubes and the preparation of the necessary materials are given by Shepherd [8]. The indicating gel tubes are made of 7-mm Pyrex glass tubing and are about $12 \mathrm{~cm}$ long. The packing consists of a small piece of Fiberglas tape, ${ }^{2} 4.5$ $\mathrm{cm}$ of guard gel, $14 \mathrm{~mm}$ of indicating gel, $2.5 \mathrm{~cm}$ of guard gel, and a second piece of Fiberglas tape. The guard gel is purified silica gel. The indicating gel is purified silica gel impregnated with a palladium and a molybdenum solution. The purification and preparation of the materials must be done with great care.

After the apparatus is assembled, the air is swept out of the system with a stream of helium and the furnaces are heated to the proper temperatures. The helium gas is then replaced with a stream of hydrogen to remove adsorbed oxygen from the carbon packing. When helium was used, about 1 to 2 weeks were required before a satisfactory blank was obtained, but with hydrogen a low blank was obtained in 24 hours. The flow of hydrogen is continued overnight and then replaced with helium. After the apparatus is ready for use, a slow stream of helium is maintained continuously, but the temperature of furnace (17, in fig. 2 ) is reduced to about $900^{\circ} \mathrm{C}$ overnight.

The sample is weighed in a platinum boat and introduced through the ground joint at (13, in fig. 2) into the quartz tube. The stopcocks (12), (20), and (13) are adjusted so that a stream of helium flows in reverse through furnace (17) and out at (13). After 2 hours of flushing, stopcock (13) is closed and stopcocks (12) and (20) are changed so that the gas flows forward through the furnace and out through the liquid air trap. The Dewar flask is filled with liquid air and placed around the glass spiral (21). The collecting flask (23) is filled with water and connected to the liquid-air trap. The flask (24) is lowered, and the lower stopcock on the collecting vessel is adjusted so that the rate of flow of helium is about $30 \mathrm{ml}$ per minute. The sample is then carefully decomposed by slowly advancing the burner and the gauze mantle over the section of the quartz tube that contains the platinum boat. The ignition requires from 10 to 15 minutes and is repeated to insure complete decomposition of any

\footnotetext{
2 Cotton is preferable if the tubes are used the same day they are packed.
} 
particles that may have sublimed to other parts of the tube. The second ignition requires only 10 minutes. The flow of gas is maintained until the water level in the collecting flask reaches a mark on the lower capillary arm, and then both the lower and upper stopcocks are closed. The collecting flask is disconnected from the apparatus and the upper stopcock opened momentarily to allow a small amount of air to flow into the flask to restore atmospheric pressure-oxygen introduced at this point does not interfere with the determination of carbon monoxide. The temperature and pressure in the room are noted.

To determine the percentage by volume of carbon monoxide in the collected gas, the flask is connected through a flow meter to an NBS indicating tube and the gas passed through the tube at a rate of $70 \mathrm{ml}$ per minute for a definite period (10 to 180 seconds, depending upon the concentration of $\mathrm{CO}$ ). The color formed in the indicating tube is then compared visually with standard tubes prepared at the same time by passing known amounts of carbon monoxide through them. Standard mixtures of carbon monoxide and air are used for this purpose. Detailed directions for the preparation of standards, reagents, and tubes are given in reference [8]. From the value obtained for the percentage by volume of carbon monoxide in the collected gas, the volume of the collected gas (which is known by previous calibration of the flask), the density of carbon monoxide at the temperature and pressure of the room, and the weight of the sample, it is possible to calculate the percentage of oxygen in the material. The calculation may be made with the following equation:

$$
\text { Percentage of } \mathrm{O}_{2}=\frac{t_{s} \times S \times V \times d \times 0.571}{t_{x} \times W},
$$

where $t_{S}$ and $t_{X}$ are the times of flow in seconds of the standard carbon monoxide mixture and the gas collected from the sample, respectively; $S$ is the percentage by volume of carbon monoxide in the standard mixture; $V$ is the volume of the collecting flask; $d$ is the density of the carbon monoxide; $W$ is the weight of the sample; and the factor 0.571 is the fraction of oxygen in carbon monoxide.

Blank determinations are made by conducting an analysis in the same manner but without a sample. The blank is about 0.001 -percent carbon monoxide 24 hours after the apparatus has been assembled, but after several weeks the blank is reduced to about 0.0002 percent of carbon monoxide.

\section{Results and Discussion}

Pure compounds containing less than 1 percent of oxygen in the molecule are not available. Therefore, two schemes were used to check the method: (1) pure compounds containing low percentages of oxygen were analyzed, and (2) mixtures of cholesterol and polystyrene, which had been analyzed previously, were prepared in varying ratios to yield samples of very small oxygen content. The results are shown in table 1.

The materials listed in table 1 were selected to determine the effect of various elements on the results. They include chlorine, bromine, nitro-

TABLE 1. Determination of oxygen in purified materials

\begin{tabular}{|c|c|c|}
\hline \multirow{2}{*}{ Substance } & \multicolumn{2}{|c|}{ Oxygen } \\
\hline & Found & $\begin{array}{l}\text { Calcu- } \\
\text { lated }\end{array}$ \\
\hline & $\begin{array}{c}\% \text { by } \\
\text { weight }\end{array}$ & $\begin{array}{c}\text { \% by } \\
\text { weight }\end{array}$ \\
\hline Dicetyl ether...... & 3.6 & 3.44 \\
\hline Do & 3.4 & 3.44 \\
\hline Do & 3.5 & 3.44 \\
\hline Cetyl stearate... & 6.3 & 6. 28 \\
\hline Do & 6.2 & 6. 28 \\
\hline $\mathrm{D}_{0} \ldots \ldots \ldots$ & 6.4 & 6.28 \\
\hline Do $\ldots \ldots . . . . .$. & 6.3 & 6. 28 \\
\hline Cholesterol_.... & 4.1 & 4. 14 \\
\hline Do $\ldots \ldots \ldots$ & 4.0 & 4. 14 \\
\hline Do & 4.1 & 4.14 \\
\hline Do & 3.9 & 4.14 \\
\hline S-(2-methoxy-5-chloro) benzylthiuronium chlor- & 6.2 & 5.99 \\
\hline $\mathrm{D}_{0}$ & 6.1 & 5. 99 \\
\hline Do & 5.9 & 5.99 \\
\hline Do 0 & 6.1 & 5.99 \\
\hline Phosphoramide, $N, N^{\prime}, N^{\prime \prime}$-tris(dibromophenyl) & 2.0 & 2.01 \\
\hline Do 0 & 1.9 & 2.01 \\
\hline Do & 1.9 & 2.01 \\
\hline Do 0 & 2.1 & 2.01 \\
\hline Cholesterol-polystyrene mixtures. & 2. 2 & 2.24 \\
\hline Do & 1.9 & 1.80 \\
\hline Do & 1.5 & 1. 51 \\
\hline Do & 1.3 & 1. 22 \\
\hline Do & 0.58 & 0.58 \\
\hline Do & .52 & .55 \\
\hline Do & .43 & .41 \\
\hline Do & .27 & .26 \\
\hline
\end{tabular}

${ }_{1}^{1}$ This compound is being prepared at the National Bureau of Standards for use as a micronalytical standard. Its structure is probably similar to that of S-benzylthiuronium chloride; however the structure of the latter compound is not definitely known. See Bougault and Charrier, Compt. rend. 218, 559 (1944). 
gen, sulfur, and phosphorus in addition to carbon, hydrogen, and oxygen. The values obtained indicate that these elements do not interfere with the method.

Inasmuch as many laboratories do not have available liquid air, the liquid-air trap was replaced with a potassium-hydroxide trap, which removes acidic substances but not unsaturated compounds, and additional analyses were made. The potassium-hydroxide trap consisted of a straight piece of Pyrex tubing, $15 \mathrm{~mm}$ in diameter and 18 $\mathrm{cm}$ long, filled with solid pellets of potassium hydroxide. Table 2 shows a comparison of the results obtained with this trap and the liquid-air trap. These results indicate that the potassiumhydroxide trap may be substituted for the liquidair trap without loss of accuracy.

TABLE 2. Relative effectiveness of liquid-air and potassium hydroxide traps

\begin{tabular}{|c|c|c|}
\hline Substance & коH trap & $\begin{array}{l}\text { Liquid-air } \\
\text { trap }\end{array}$ \\
\hline & $\begin{array}{c}\% \mathrm{O}_{2} b y \\
\text { weight }\end{array}$ & $\begin{array}{c}\% \mathrm{O}_{2} \text { by } \\
\text { weight }\end{array}$ \\
\hline Cholesterol_....... & 4.1 & 4.1 \\
\hline Do & 4. 1 & 4.0 \\
\hline Do & 3.9 & 4.1 \\
\hline Do & 4.0 & 3.9 \\
\hline $\mathrm{S}$ - (2- methoxy -5 -chloro) benzylthiuronium & & \\
\hline chloride .... & 6.0 & 6.2 \\
\hline Do & 5.9 & 6.1 \\
\hline Do $\ldots . . . . . .$. & 5.9 & 5.9 \\
\hline Do & 6.1 & 6.1 \\
\hline Polystyrene.... & 0.034 & 0.033 \\
\hline Do & .035 & .035 \\
\hline Do & .032 & .033 \\
\hline
\end{tabular}

Tests were made to determine the length of time required to sweep the system free of air after introduction of the sample. It was found that 30 minutes of reverse flushing is sufficient. However, if oxygen is adsorbed on the sample a longer time may be required as indicated by the results for anthracene listed in table 3 . If desired, the removal of adsorbed oxygen may be accelerated by placing the boat containing the sample near the end of the quartz tube and slipping over this section of the tube an electrically heated jacket filled with a liquid that boils at the temperature selected for heating the sample during the flushing period.

Oxygen determinations have been made on
TaBle 3. Determination of oxygen in miscellaneous materials

\begin{tabular}{|c|c|}
\hline Substance & Oxygen \\
\hline & $\%$ by weight \\
\hline Anthracene (reverse flushing for $2 \mathrm{hr}$ )... & 0.018 \\
\hline Do & .017 \\
\hline Anthracene (reverse flushing for $16 \mathrm{hr}$ ). & .015 \\
\hline Do & .012 \\
\hline Diphenyl & .011 \\
\hline Do & .014 \\
\hline Natural rubber (unextracted) & .8 \\
\hline GRS rubber (unextracted) & .9 \\
\hline Butyl rubber (unextracted) $\ldots$ & .4 \\
\hline Gutta percha (unextracted) & 1. 0 \\
\hline Popcorn polystyrene & 0.034 \\
\hline Diesel oil (Fischer-Tropsch) ....... & .14 \\
\hline Vistanex (dried $3 \mathrm{hr}$ at $\left.90^{\circ} \mathrm{C}\right)$ & .047 \\
\hline Vistanex (dried $3 \mathrm{hr}$ at $90^{\circ}$ and $3 \mathrm{hr}$ at $120^{\circ} \mathrm{C}$ ) & .50 \\
\hline Vistanex (dried $48 \mathrm{hr}$ at $\left.150^{\circ} \mathrm{C}\right) \ldots$ & 2. 6 \\
\hline
\end{tabular}

various materials, and a few of these are listed in table 3 .

The low values reported in the table for the oxygen content of anthracene and diphenyl were obtained on samples that had been carefully purified. Original samples of these materials contained as much as 0.35 percent of oxygen, and it was possible to follow the purification by the gradual reduction in the percentage of oxygen present. The diesel oil was a sample made in Germany by the Fischer-Tropsch process.

The results obtained with Vistanex are very interesting. In connection with another problem, it had been noted previously by one of the authors that polystyrene, when precipitated in a finely divided state, slowly gained in weight when heated at $50^{\circ} \mathrm{C}$. This rate of increase in weight was accelerated at $70^{\circ} \mathrm{C}$. The results obtained with Vistanex clearly show that its oxygen content increases with increase in temperature and period of heating. Similar results were obtained with dicetyl ether.

\section{References}

[1] C. Dufraisse, Rev. gén. caoutchouc 9, No. 85, 3 (1932); Rubber Chem. and Tech. 6, 152 (1933).

[2] P. J. Elving and W. B. Ligett, Chem. Rev. 34, 129 (1944).

[3] M. Schütze, Naturwissenschaften 27, 822 (1939).

[4] M. Schütze, Z. anal. Chem. 118, 241 (1939).

[5] M. Schütze, Z. anal. Chem. 118, 245 (1939).

[6] J. Unterzaucher, Ber. deut. chem. Ges. $\mathbf{3 3 b}, 391$ (1940).

[7] V. A. Aluise, R. T. Hall, F. C. Statts, and W. W. Becker, Anai. Chem. 19, 347 (1947).

[8] M. Shepherd, Anal. Chem. 19, 77 (1947).

Washington, February 6, 1948. 